\title{
Attention deficit hyperactivity disorder may be a highly inflammation and immune-associated disease (Review)
}

\author{
RONG-YI ZHOU $^{1 *}$, JIAO-JIAO WANG $^{1 *}$, JI-CHAO SUN $^{1}$, YUE YOU $^{1}$, JING-NANG YING $^{2}$ and XIN-MIN HAN ${ }^{1}$ \\ ${ }^{1}$ First Clinical Medical College, Nanjing University of Chinese Medicine, Nanjing, Jiangsu 210023; ${ }^{2}$ Department of Pediatrics, \\ The Second Affiliated Hospital of Nanjing Medical University, Nanjing, Jiangsu 210011, P.R. China
}

Received October 10, 2016; Accepted June 1, 2017

DOI: $10.3892 / \mathrm{mmr} .2017 .7228$

\begin{abstract}
Attention deficit hyperactivity disorder (ADHD) is a common behavioral disorder. Previous research has indicated that genetic factors, family education, environment and dietary habits are associated with ADHD. It has been determined that in China many children with ADHD also have allergic rhinitis or asthma. These children are more susceptible to the common cold or upper respiratory infections compared with normal healthy children. Additionally, the common cold or an upper respiratory infection may lead to disease recurrence or worsen the symptoms in these children. Previous studies have determined that ADHD may have a close association with allergic disease. Based on the clinically observed phenomenon and previous studies, it was hypothesized that ADHD is a high inflammation and immune-associated disease. Therefore, the authors designed clinical and animal experiments to test this hypothesis in the future. Immune system disorders may be a novel part of the etiology of ADHD. The current report may have implications for future clinical practice.
\end{abstract}

Correspondence to: Professor Xin-Min Han, First Clinical Medical College, Nanjing University of Chinese Medicine, 138 Xianlin Road, Qixia, Nanjing, Jiangsu 210023, P.R. China

E-mail: hxm1nj@126.com

*Contributed equally

Abbreviations: ADHD, attention deficit hyperactivity disorder; DA, dopamine; NE, norepinephrine; MPH, methylphenidate; CNS, central nervous system; AE, atopic eczema; AR, allergic rhinitis; BBB, blood-brain barrier; SHR, spontaneously hypertensive rats; WKY, Wistar Kyoto mice; HPLC, high-performance liquid chromatography; TH, tyrosine hydroxylase; SNAP25, synaptosoma associated protein 25; VMAP2, vesicle-associated membrane protein 2; DAT, dopamine transporter; DDC, DOPA decarboxylase; syntaxin1A, synaptic fusion protein $1 \mathrm{~A}$; TNF- $\beta$, tumor necrosis factor- $\beta$

Key words: ADHD, allergic disease, immune system, clinical treatment

\section{Contents}

1. Introduction

2. Potential relationship between ADHD and allergic disease

3. Potential mechanisms

4. Hypothesis: ADHD may be a highly inflammation and immune-related disease

5. Testing the hypotheses

6. Implications for clinical practice of this hypothesis

7. Conclusions

\section{Introduction}

Attention deficit hyperactivity disorder (ADHD) is a common behavioral disorder with an onset during childhood. Currently, ADHD has a prevalence of 5.9\% worldwide (1). The core symptoms of ADHD are inattention, impulsiveness and hyperactivity $(2,3)$. These negative effects may cause serious problems to the individual, family and society. Previous studies have revealed that ADHD has been associated with criminal activity (4-6). Although previous studies have indicated that genetic factors $(7,8)$, streptococcal infection $(9,10)$ and environmental factors (11-13) were closely associated with ADHD, to the best of our knowledge, the causes of ADHD remain to be fully elucidated. However, the theory of dopamine (DA) deficiency in ADHD currently widely accepted (14). In addition, other mechanism-based hypotheses, involving norepinephrine (NE) $(15)$ and serotonin $(16,17)$ have also been proposed for ADHD. However, these hypotheses require further investigation for confirmation. Currently, pharmacological and psychosocial interventions are the most frequently used methods of treatment (18). Methylphenidate (MPH) is the first choice and first-line medical treatment for ADHD for adults and children (18). However, it has a number of serious side effects, such as depression, anxiety and obsessive compulsive symptoms $(19,20)$, parents are disinclined to use MPH and nonadherence to therapy is high (21) under these circumstances, novel insights into the causes and treatment methods for ADHD are necessary.

In China, many children with ADHD have also been diagnosed with allergic rhinitis (AR) or asthma. In addition, children with ADHD are more susceptible to the common cold or upper respiratory infections compared with normal healthy 
children. In children with ADHD with controlled clinical symptoms, common colds or upper respiratory infections may lead to AR or asthma disease relapse and reduced immune function. This may result in the recurrence or exacerbation of ADHD symptoms $(22,23)$. Additionally, this phenomenon is common rather than the exception and the underlying reasons for this occurrence remain to be elucidated. At present, clinicians have not devoted sufficient attention to this phenomenon. Nonetheless, it has a major role in other complex genetic diseases, such as AR and asthma (24). A previous study indicates that AR and asthma, which are immune-associated diseases may also be associated with ADHD (25). Therefore, it is possible that ADHD may be associated with the immune system and that the immune system may underlie ADHD onset or recurrence. Therefore, the immune system should receive more attention and consideration in the clinical treatment of ADHD.

\section{Potential relationship between ADHD and allergic disease}

ADHD is deemed to be a neurobehavioral disorder, DA deficiency in the central nervous system (CNS) is one recognized as part of the pathogenesis of ADHD (14). Previous studies have revealed that ADHD may impair affected children and impose a significant economic burden on their families and society in general $(1,26,27)$. In addition, a previous study has indicated that ADHD has a moderate association with criminal activity, a significant risk of suicide, and has a negative effect on the labor market outcomes. Therefore, ADHD requires more attention. AR, which is an immune-associated disease, which has recently been shown to have an association with ADHD (25). However, the association between CNS diseases and allergic diseases remains to be elucidated.

Allergic diseases, such as atopic eczema (AE), AR and allergic asthma, are common childhood chronic illnesses that are estimated to affect 7 to $40 \%$ of children worldwide (28). With the deterioration of the environment due to pollution, the morbidity of allergic diseases has increased over time (29-31). Recently, researchers have paid close attention to the connection between ADHD and allergic disease $(32,33)$. Previous reports have revealed potential associations between ADHD and allergic diseases (34-36). AE, AR, and allergic asthma are considered to be the most common chronic diseases worldwide and represent the three major clinical manifestations of atopy (37). The characteristic symptoms of AR are itching, rhinorrhea, and nasal congestion and obstruction. These symptoms may result in daytime inattention, irritability and hyperactivity, which are also symptoms of ADHD. Previous studies have indicated that there are associations between ADHD and AR (38-40). Brawley et al reported that 10 out of $23(43 \%)$ children with ADHD had typical physical signs of AR (41). A population-based study from Taiwan indicated that patients with ADHD had an increased occurrence of AR compared with normal healthy subjects (42). Children with AR have hyperactivity and impulsivity (43). Risk factors for inattention and impulsivity in children with AR may lead to comorbidity with ADHD (43). AE, which is another allergic disease, has also been identified to have a significant association with ADHD in a large population-based sample (44).
Schmitt et al reported that AE is independently associated with ADHD (45). In addition, an epidemiological survey revealed that children with AE have a significantly higher risk for ADHD-symptoms (38). The potential mechanisms underlying the comorbidity of AE and ADHD may be associated with high levels of psychological stress (46), genetic factors (47) and interference of inflammatory cytokines with the maturation of the prefrontal cortex regions and neurotransmitter systems involved in ADHD pathology (37). Allergic asthma, a leading cause of childhood chronic medical illness, affects $7-15 \%$ of children worldwide (48). Previous population-based studies $(28,49,50)$ have indicated significant associations between allergic asthma and ADHD. Children with asthma have a higher incidence of ADHD compared with normal healthy children. Based on the aforementioned evidence, allergic diseases, such as AE, AR and allergic asthma may have a significant connection with ADHD. However, the potential mechanisms underlying the comorbidity of allergic diseases and ADHD remain to be elucidated.

\section{Potential mechanisms}

At present, the specific association between allergic diseases and ADHD is in the hypotheses and preliminary study stage. Therefore, the potential mechanisms underlying the comorbidity of allergic diseases and ADHD remain to be determined. Previous investigations using molecular biology have provided some possible explanations for the association between allergic diseases and ADHD. Buske-Kirschbaum et al (51) have proposed that children with atopic disease are exposed to higher levels of inflammatory cytokines released during the atopic response and these cytokines may then pass through the blood-brain barrier (BBB) (52) and interfere with the development of brain regions, such as the prefrontal cortex, the corpus striatum, and the DA system, which have crucial roles in executive functions, such as attention, motivation motor, and cognitive control (37,53-55). Conversely, Rosenkranz et al (56) revealed that emotional behaviors are mediated by the prefrontal cortex, such as attention, are activated during atopic episodes, as demonstrated by functional magnetic resonance imaging. Inflammatory mediators significantly affect the evaluation of sensory stimulation and the regulation of homeostatic responses in the prefrontal cortex and the insula. Therefore, inflammatory mediators levels may be used to identify children vulnerable to the risk of developing ADHD symptoms. Studies $(47,57)$ have stated that genetic factors are associated with ADHD and allergic diseases, and that AE and ADHD are complex multifactorial traits with substantial genetic components. Prenatal stress has been reported as another factor contributing to ADHD. A previous study revealed that maternal stress during pregnancy may be associated with psychopathology later in life, including symptoms of attention deficit, compulsive behavior and hyperactivity (58). There are various theories on the potential mechanisms underlying the comorbidity of allergic diseases and ADHD. The aforementioned theories identified the relationships among inflammation, immunity and allergic diseases. Although these theories vary substantially, they are unanimous regarding the presence of a clear connection between ADHD and allergic diseases and provide evidence for this idea. ADHD and allergic 
diseases may share molecular mechanisms, which may need to be determined in future studies.

\section{Hypothesis: ADHD may be a highly inflammation and immune-related disease}

There is substantial evidence that allergic diseases, such as $\mathrm{AE}, \mathrm{AR}$, and allergic asthma, have significant association with ADHD. The majority of children with ADHD have a strong association with allergic diseases (25). Allergic diseases and the allergic response are associated with the immune system and inflammation $(59,60)$. Typical allergic diseases, such as $\mathrm{AE}, \mathrm{AR}$, and allergic asthma lead to significant responses reflected in the immunoglobulin $(\mathrm{Ig}) \mathrm{E}$ or IgG levels and T cell changes in clinical studies $(24,61,62)$. Researchers $(23,63,64)$ reported that ADHD has high comorbidity with helper T cell (Th)1- and Th2-mediated disorders, such as ear infections, eczema and asthma. Substantial alterations occur in the immune system and the epigenetic regulation of gene expression in ADHD. Overall, it is evident that different types of allergic diseases are heterogeneous with respect to the role of the immunopathology underlying the cause of these diseases. Although ADHD has never been postulated as an allergic disorder, the present study hypothesizes that ADHD has an etiologic connection with the immune system and inflammation. Therefore, it is possible that ADHD is an inflammation and immune-associated disease.

The current study has presented sufficient evidence to support this hypothesis. Mervan Bekdas (65) performed a clinical study on patients with ADHD and healthy children and quantified their IgG levels. The findings indicated that ADHD is associated with a significant immune reaction $(\mathrm{P}=0.044)$. Another study (66) revealed a significant positive association between ADHD and the anti-Yo antibody immunoreactivity in the Purkinje cells of the cerebellum in children and suggested the presence of immune dysregulation in children with ADHD. These clinical studies offered additional evidence that may be used to identify relationships between ADHD and immunity. It has been previously reported (23) that patients with ADHD have elevated concentration of the innate pro-inflammatory cytokine tumor necrosis factor (TNF)- $\beta$ and reduced levels of anti-inflammatory cytokines interleukin (IL)-4, IL-2 and interferon $\gamma$ (IFN- $\gamma$ ). In addition, mothers suffering from inflammatory and immune system diseases during the prenatal period have an increased the risk of their offspring developing ADHD (67). Inflammatory cytokines may interfere with the maturation of the prefrontal cortex regions and neurotransmitter systems (51) associated with DA systems. Peripheral inflammation may lead to the occurrence of ADHD. This may be due to microglial activation and TNF- $\alpha$ production mediating altered CNS excitability (68). The microbiota-gut-brain axis (MGB) theory has been previously proposed and provided evidence regarding the connection between ADHD and maternal inflammation (69). Previous studies have determined that gut microbes are associated with the body's immune system and that gut microbes aid in the maintenance of homeostasis and ensure the normal operation of the immune system by mutual exchange of cytokines with the intestinal epithelium and intestinal mucosal cells $(70,71)$. The gut microbiota may also pass through the BBB and influence the CNS immune system (72). It is of note that children with ADHD have been recoded to have abnormalities in the MGB (73). This supports the hypothesis that ADHD is an immune-associated disease.

The previous studies provide evidence that the immune system and inflammation may be associated with the underlying mechanisms of ADHD. Based on the aforementioned evidence the present study hypothesized that ADHD may be closely associated with the immune system and inflammation, and that ADHD is an inflammation- and immune-associated disease.

\section{Testing the hypotheses}

There are two methods to test the hypotheses: Clinical research and animal experiments. T-lymphocytes have an important role in the immune system. The $\mathrm{CD} 4^{+}$(helper) to $\mathrm{CD} 8^{+}$(cytotoxic) ratio has been used to assess a person's level of immunity. For preliminary clinical research, the CD4/CD8 ratio in blood samples of children with ADHD may be quantified using flow cytometry. This ratio may then be compared to that obtained from normal children to provide basic evidence that may be used to prove our hypotheses. For further research, the levels of other T, B and natural killer (NK)-cells, and immune-associated proteins should also be quantified in future studies. Detailed research methods for the above experiments are presented in Fig. 1. For animal experiments, the spontaneously hypertensive rats (SHR) model is deemed the best recognized ADHD animal model (74), which may be compared with normotensive Wistar Kyoto (WKY) control rats (75). SHR rats have typical ADHD symptoms at 3-4 weeks of age (76). Flow cytometry may be used to quantify the blood and spleen T, B and NK-cell levels in the rats. Furthermore, DA levels in the striatum and prefrontal cortex may also be quantified using high-performance liquid chromatography. IgG quantification may be performed using enzyme-linked immunosorbent assay or reverse transcription-polymerase chain reaction, whereas tyrosine hydroxylase (TH) levels may be determined using immunofluorescence or immunohistochemistry. Detailed research methods are presented in Fig. 2. The aforementioned research design may aid in elucidating the association between ADHD and immunity, and determine whether ADHD is an immune-associated disease.

\section{Implications for clinical practice of this hypothesis}

The present study suggests that when clinicians treat children with ADHD, they should consider inflammation and immunity, not just genetic factors or lower dopamine levels. If the patient has an allergic disease such as AR, AE, or allergic asthma, then more attention should be paid to the inflammatory cytokines and the immune system. An immunological clinical inspection and an accurate and timely allergy and immune system diagnosis are required and important for treating the patient in an appropriate manner (77). The present study provides a novel way of examining the clinical treatment of ADHD. Therefore, physicians should also consider the immune system. The clinical phenomenon observed in China, where children with ADHD are more susceptible to the common cold or upper respiratory infections, to the best of our knowledge, not been 


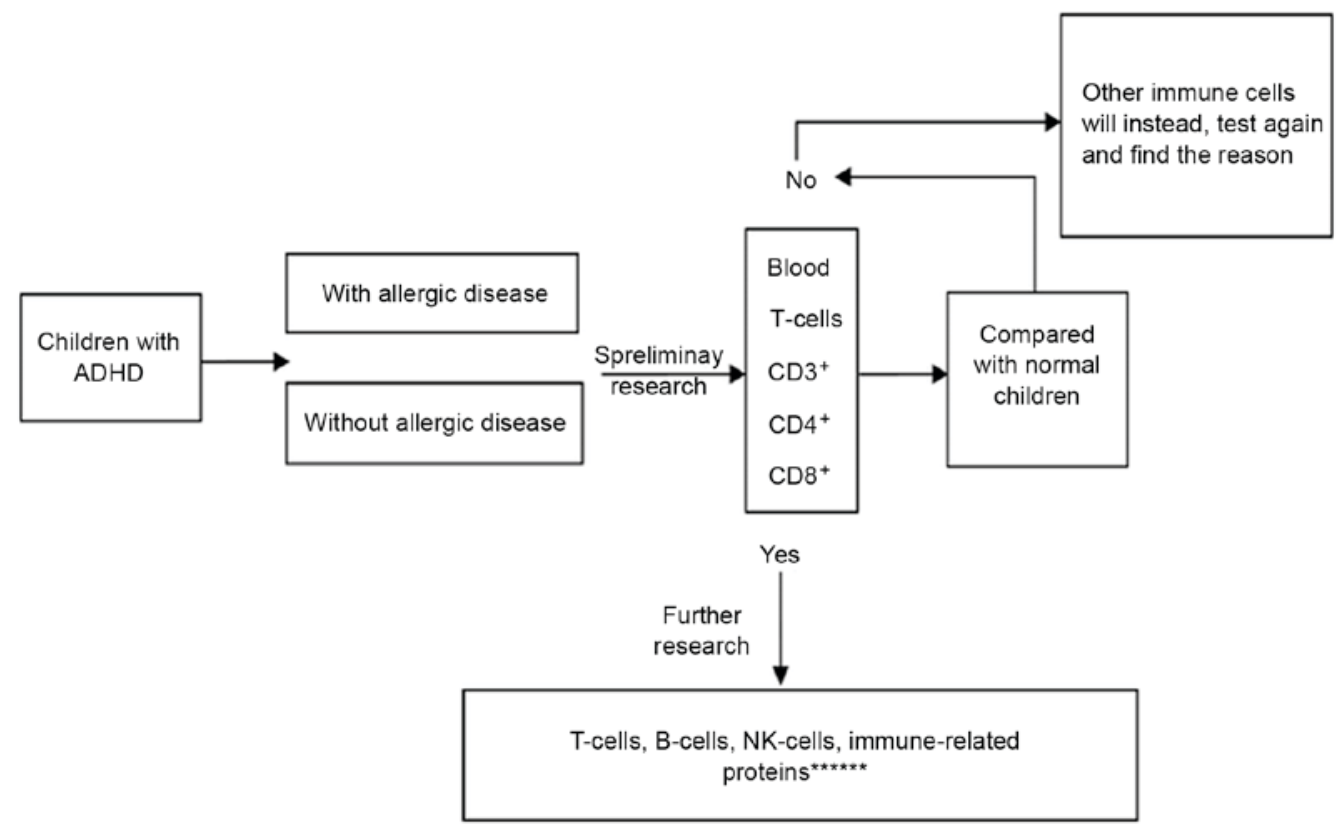

Figure 1. Clinical research design. Children with ADHD will be divided into two groups depending on presence of allergic disease and blood samples will be compared with those from normal children. For preliminary research, T-lymphocytes CD3/CD4/CD8 will be detected. In case of a significant change in immunity, additional immune-associated indicators will be quantified. If not, other immune cells or immune-associated factors will be tested to determine the underlying mechanisms. ADHD, attention-deficit hyperactivity disorder; NK, natural killer.

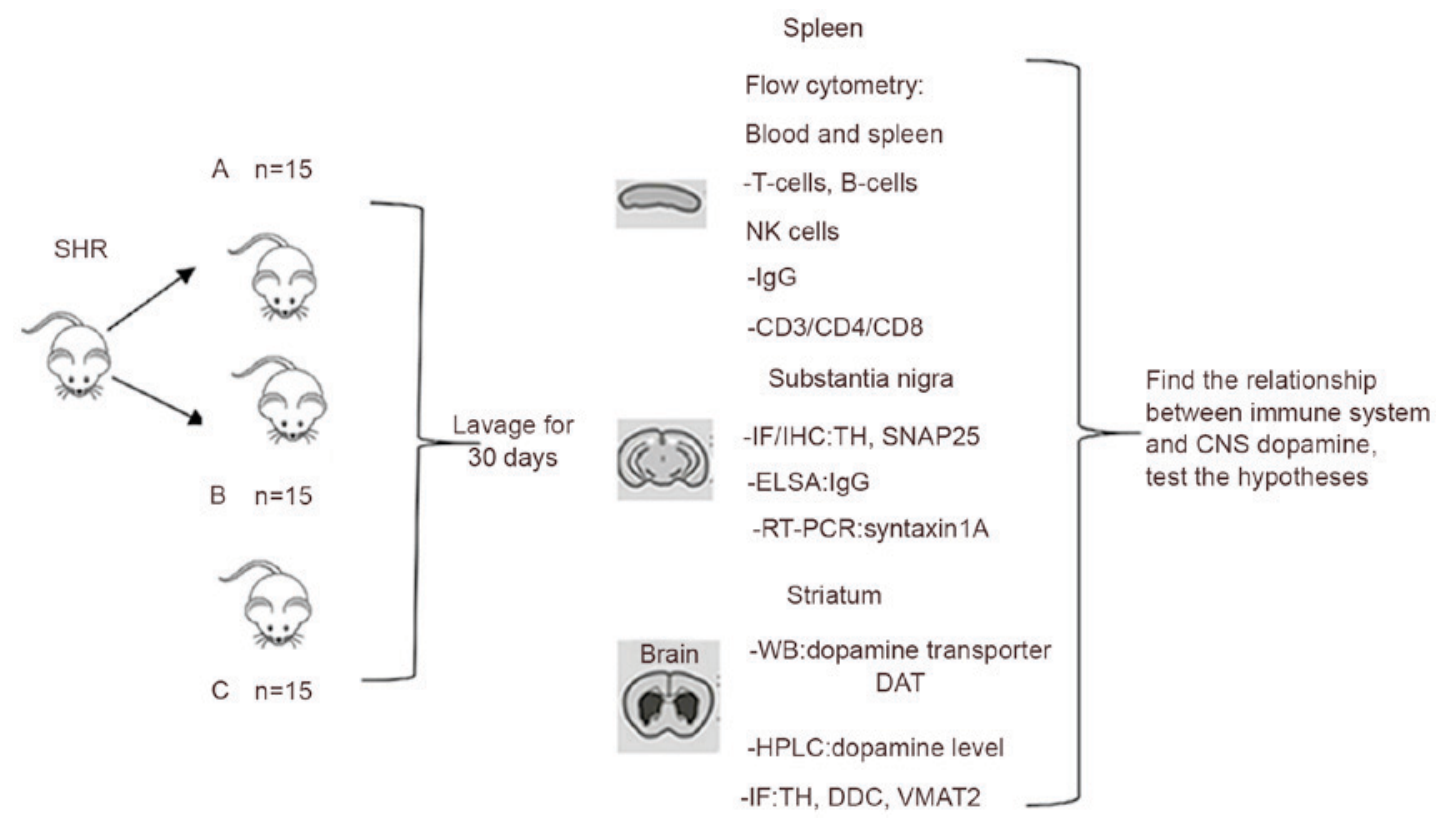

Figure 2. Animal experimental design. Mice will be divided into 3 groups, the control group A (lavage with Ritalin), the model group B (lavage with saline) and the blank group C (lavage with saline), with and will be treated with lavage for 30 days. Blood and spleen samples will be tested using flow cytometry for $\mathrm{CD} 3 / \mathrm{CD} 4 / \mathrm{CD} 8, \mathrm{~B}$ and $\mathrm{NK}$ cells, and IgG to determine whether ADHD model mice have immune problems. Immunofluorescence or immunohistochemistry, ELISA and reverse transcription polymerase chain reaction will be used to detect ADHD-associated proteins, such as syntaxin1A, DDC, VMAT) and SNAP25 in the substantia nigra. The striatum dopamine levels will be confirmed using HPLC. Other appropriate methods, including microdialysis technology, gene chip technology and metabolomics technology will be used to determine the association between the immune system and CNS dopamine levels in the CNS. SHR, spontaneously hypertensive rats; ADHD, attention-deficit hyperactivity disorder; NK, natural killer; IF, immunofluorescence; IHC, immunohistochemistry; WB, western blotting; CNS, central nervous system; syntaxin1A, synaptic fusion protein 1A; DDC, DOPA decarboxylase; VMAT2, vesicular monoamine transporter 2; SNAP25, synaptosoma associated protein 25; DAT, dopamine transporter; HPLC, high-performance liquid chromatography.

widely considered in the medical community. The present study is based on this clinical phenomenon, if it is confirmed children with ADHD may be divided into immune-associated and non-immune-associated ADHD. Subsequently, therapies aimed to regulate immunity instead of central stimulant drugs such as methylphenidates may be used. This may aid in reducing the application of psychiatric drugs and the mental stress in children with ADHD and their families, and improve the quality of life for children and adults with ADHD in the future. 


\section{Conclusions}

ADHD is deemed to be a neurobehavioral disorder due to CNS DA deficiency, the specific etiology and pathogenesis remain to be elucidated. The association among ADHD, allergic diseases and the immune system have not been fully investigated in the clinical and laboratory setting. In the clinical setting in China, many children with ADHD also suffered from allergic diseases, such as AR and asthma and children with ADHD are more susceptible to the common cold or upper respiratory infections compared with normal healthy children. They also have relapses of AR or asthma, which may lead to ADHD symptom recurrence or deterioration. This phenomenon also exists in other countries, including Korea and Germany $(38,42)$. Based on the aforementioned findings the present study determined that ADHD may be associated with allergic diseases and that it may be immune-associated disease. However, not enough attention has been devoted to this phenomenon by clinicians. Investigating this phenomenon may provide clinicians with a novel way of thinking in terms of the clinical treatment of ADHD. Clinicians may alter their clinical conception and investigate the immune system extensively. To test the connection between ADHD and the immune system, the present study designed preliminary clinical and animal experiments. In the clinical research proposal, children may be divided into two groups: Children with ADHD and normal children. Blood IgG, CD4/CD8 ratio, NK cell levels, and other immune-associated factors may be quantified using flow cytometry to indicate the association between ADHD and the immune system. In the animal experiments, the aforementioned immune-associated factors would also be measured. In addition, the relationship between the immune system and CNS dopamine levels may be investigated in order to find out whether immunity may influence the DA levels in the CNS. This hypothesis may have a significant effect in the clinical setting, where children with ADHD may be divided into immune-associated and non-immune-associated ADHD groups. Methods to regulate immunity may be used instead of central stimulant drugs such as methylphenidates. This may reduce the application of psychiatric drugs and the mental stress in children with ADHD and their families, and improve the quality of life for children and adults with ADHD in the future.

\section{Acknowledgments}

The present study was supported by the National Natural Science Foundation of China (grant nos. 81674023 and 81273801).

\section{References}

1. Polanczyk G, de Lima MS, Horta BL, Biederman J and Rohde LA: The worldwide prevalence of ADHD: A systematic review and metaregression analysis. Am Psychiatry 164: 942-948, 2007.

2. Antle MC, van Diepen HC, Deboer T, Pedram P, Pereira RR and Meijer JH: Methylphenidate modifies the motion of the circadian clock. Neuropsychopharmacology 37: 2446-2455, 2012.

3. Davis C, Levitan RD, Smith M, Tweed S and Curtis C: Associations among overeating, overweight, and attention deficit/ hyperactivity disorder: A structural equation modelling approach. Eat Behav 7: 266-274, 2006.
4. Lichtenstein P, Halldner L, Zetterqvist J, Sjölander A, Serlachius E, Fazel S, Långström N and Larsson H: Medication for attention deficit hyperactivity disorder and criminality. N Engl J Med 367: 2006-2014, 2012.

5. Satterfield JH, Faller KJ, Crinella FM, Schell AM, Swanson JM and Homer LD: A 30-year prospective follow-up study of hyperactive boys with conduct problems: Adult criminality. J Am Acad Child Adolesc Psychiatry 46: 601-610, 2007.

6. Fletcher JM: The effects of childhood ADHD on adult labor market outcomes. Health Econ 23: 159-181, 2014.

7. Lichtenstein P, Carlström E, Råstam M, Gillberg C and Anckarsäter H: The genetics of autism spectrum disorders and related neuropsychiatric disorders in childhood. Am J Psychiatry 167: 1357-1363, 2010.

8. Paloyelis Y, Rijsdijk F, Wood AC, Asherson P and Kuntsi J: The genetic association between ADHD symptoms and reading difficulties: The role of inattentiveness and IQ. J Abnorm Child Psychol 38: 1083-1095, 2010.

9. Leslie DL, Kozma L, Martin A, Landeros A, Katsovich L, King RA and Leckman JF: Neuropsychiatric disorders associated with streptococcal infection: A case-control study among privately insured children. J Am Acad Child Adolesc Psychiatry 47: 1166-1172, 2008.

10. Li E, Ruan Y, Chen Q, Cui X, Lv L, Zheng P and Wang L: Streptococcal infection and immune response in children with Tourette's syndrome. Childs Nerv Syst 31: 1157-1163, 2015.

11. Meaney MJ: Epigenetics and the biological definition of gene $x$ environment interactions. Child Dev 81: 41-79, 2010.

12. Thapar A, Cooper M, Jefferies R and Stergiakouli E: What causes attention deficit hyperactivity disorder? Arch Dis Child 97: 260-265, 2012.

13. Mulligan A, Anney R, Butler L, O'Regan M, Richardson T, Tulewicz EM, Fitzgerald $\mathrm{M}$ and Gill M: Home environment: Association with hyperactivity/impulsivity in children with ADHD and their non-ADHD siblings. Child Care Health Dev 39: 202-212, 2013.

14. Swanson JM, Kinsbourne M, Nigg J, Lanphear B, Stefanatos GA, Volkow N, Taylor E, Casey BJ, Castellanos FX and Wadhwa PD: Etiologic subtypes of attention-deficit hyperactivity disorder: Brain imaging, molecular genetic and environmental factors and the dopamine hypothesis. Neuropsychol Rev 17: 39-59, 2007.

15. Schmeichel BE and Berridge CW: Neurocircuitry underlying the preferential sensitivity of prefrontal catecholamines to low-dose psychostimulants. Neuropsychopharmacology 38: 1078-1084, 2013.

16. Humby T, Eddy JB, Good MA, Reichelt AC and Wilkinson LS: A novel translational assay of response inhibition and impulsivity: Effects of prefrontal cortex lesions, drugs used in ADHD, and serotonin $2 \mathrm{C}$ receptor antagonism. Neuropsychopharmacology 38: 2150-2159, 2013

17. Trent S, Cassano T, Bedse G, Ojarikre OA, Humby T and Davies W: Altered serotonergic function may partially account for behavioral endophenotypes in steroid sulfatase-deficient mice. Neuropsychopharmacology 37: 1267-1274, 2012.

18. McCarthy S, Wilton L, Murray ML, Hodgkins P, Asherson P and Wong IC: The epidemiology of pharmacologically treated attention deficit hyperactivity disorder (ADHD) in children, adolescents and adults in UK primary care. BMC Pediatr 12: 78, 2012.

19. Gürkan K, Bilgiç A, Türkoglu S, Kiliç BG, Aysev A and Uslu R: Depression, anxiety and obsessive compulsive symptoms and quality of life in children with attention-deficit hyperactivity disorder (ADHD) during three-month methylphenidate treatment. J Psychopharmacol 24: 1810-1818, 2010.

20. Sadasivan S, Pond BB, Pani AK, Qu C, Jiao Y and Smeyne RJ: Methylphenidate exposure induces dopamine neuron loss and activation of microglia in the basal ganglia of mice. PLoS One 7: e33693, 2012.

21. Charach A and Fernandez R: Enhancing ADHD medication adherence: Challenges and opportunities. Curr Psychiatry Rep 15: 371-379, 2013.

22. Giana G, Romano E, Porfirio MC, D'Ambrosio R, Giovinazzo S, Troianiello M, Barlocci E, Travaglini D, Granstrem O, Pascale E, et al: Detection of auto-antibodies to DAT in the serum: Interactions with DAT genotype and psycho-stimulant therapy for ADHD. J Neuroimmunol 278: 212-222, 2015.

23. Verlaet AA, Noriega DB,Hermans N and Savelkoul HF: Nutrition, immunological mechanisms and dietary immunomodulation in ADHD. Eur Child Adolesc Psychiatry 23: 519-529, 2014. 
24. Kohlboeck G, Koletzko S, Bauer CP, von Berg A, Berdel D, Krämer U, Schaaf B, Lehmann I, Herbarth O, Heinrich J, et al: Association of atopic and non-atopic asthma with emotional symptoms in school children. Pediatr Allergy Immunol 24: 230-236, 2013.

25. Tsai JD, Chang SN, Mou CH, Sung FC and Lue KH: Association between atopic diseases and attention-deficit/hyperactivity disorder in childhood: A population-based case-control study. Ann Epidemiol 23: 185-188, 2013.

26. Birnbaum HG, Kessler RC, Lowe SW, Secnik K, Greenberg PE, Leong SA and Swensen AR: Costs of attention deficit-hyperactivity disorder (ADHD) in the US: Excess costs of persons with ADHD and their family members in 2000. Curr Med Res Opin 21 195-206, 2005

27. Cuffe SP, Moore CG and McKeown R: ADHD and health services utilization in the national health interview survey. J Atten Disord 12: 330-340, 2009.

28. Kwon HJ, Lee MY, Ha M, Yoo SJ, Paik KC, Lim JH, Sakong J, Lee CG, Kang DM, Hong SJ, et al: The associations between ADHD and asthma in Korean children. BMC Psychiatry 14: 70, 2014.

29. Björkstén B, Clayton T, Ellwood P, Stewart A and Strachan D; ISAAC Phase III Study Group: Worldwide time trends for symptoms of rhinitis and conjunctivitis: Phase III of the International Study of Asthma and Allergies in Childhood. Pediatr Allergy Immunol 19: 110-124, 2008.

30. Shamssain M: Trends in the prevalence and severity of asthma, rhinitis and atopic eczema in 6- to 7- and 13- to 14-yr-old children from the north-east of England. Pediatr Allergy Immunol 18: 149-153, 2007.

31. Cutuli JJ, Herbers JE, Rinaldi M, Masten AS and Orberg CN: Asthma and behavior in homeless 4- to 7-year-olds. Pediatrics 125 145-151, 2010.

32. Miyazaki C, Koyama M, Ota E, Swa T, Mlunde LB, Amiya RM, Tachibana Y, Yamamoto-Hanada K and Mori R: Allergic diseases in children with attention deficit hyperactivity disorder: A systematic review and meta-analysis. BMC Psychiatry 17: 120 2017.

33. Feng B, Jin H, Xiang H, Li B, Zheng X, Chen R, Shi Y, Chen S and Chen B: Association of pediatric allergic rhinitis with the ratings of attention-deficit/hyperactivity disorder. Am J Rhinol Allergy 31: 161-167, 2017

34. Lin YT, Chen YC, Gau SS, Yeh TH, Fan HY, Hwang YY and Lee YL: Associations between allergic diseases and attention deficit hyperactivity/oppositional defiant disorders in children. Pediatr Res 80: 480-485, 2016.

35. Holmberg K, Lundholm C, Anckarsäter H, Larsson H and Almqvist C: Impact of asthma medication and familial factors on the association between childhood asthma and attention-deficit/ hyperactivity disorder: A combined twin- and register-based study: Epidemiology of allergic disease. Clin Exp Allergy 45 964-973, 2015.

36. Schans JV, Çiçek R, de Vries TW, Hak E and Hoekstra PJ: Association of atopic diseases and attention-deficit/hyperactivity disorder: A systematic review and meta-analyses. Neursci Biobehav Res 74: 139-148, 2017.

37. Buske-Kirschbaum A, Schmitt J, Plessow F, Romanos M, Weidinger S and Roessner V: Psychoendocrine and psychoneuroimmunological mechanisms in the comorbidity of atopic eczema and attention deficit/hyperactivity disorder. Psychoneuroendocrinology 38: 12-23, 2008.

38. Romanos M, Gerlach M, Warnke A and Schmitt J: Association of attention deficit/hyperactivity disorder and atopic eczema modified by sleep disturbance in a large population-based sample. J Epidemiol Community Health 64: 269-273, 2010.

39. Brawley A, Silverman B, Kearney S, Guanzon D, Owens M, Bennett $\mathrm{H}$ and Schneider A: Allergic rhinitis in children with attention-deficit/hyperactivity disorder. Ann Allergy Asthma Immunol 92: 663-667, 2004

40. Suwan P, Akaramethathip D and Noipayak P: Association between allergic sensitization and attention deficit hyperactivity disorder (ADHD). Asian Pac J Allergy Immunol 29: 57-65, 2011

41. Brawley A, Silverman B, Kearney S, Guanzon D, Owens M, Bennett $\mathrm{H}$ and Schneider A: Allergic rhinitis in children with attention-deficit/hyperactivity disorder. Ann Allergy Asthma Immunol 92: 663-667, 2004

42. Chou PH, Lin CC, Lin CH, Loh el-W, Chan CH and Lan TH: Prevalence of allergic rhinitis in patients with attentiondeficit/hyperactivity disorder: A population-based study. Eur Child Adolesc Psychiatry 22: 301-307, 2013.
43. Yang MT, Lee WT, Liang JS, Lin YJ, Fu WM and Chen CC: Hyperactivity and impulsivity in children with untreated allergic rhinitis: Corroborated by rating scale and continuous performance test. Pediatr Neonatol 55: 168-174, 2014.

44. Romanos M, Gerlach M, Warnke A and Schmitt J: Association of attention-deficit/hyperactivity disorder and atopic eczema modified by sleep disturbance in a large population-based sample. J Epidemiol Community Health 64: 269-273, 2010.

45. Schmitt J, Romanos M, Schmitt NM, Meurer M and Kirch W: Atopic eczema and attention-deficit/hyperactivity disorder in a population-based sample of children and adolescents. JAMA 301: 724-726, 2009.

46. Magin P, Adams J, Heeding G, Pond D and Smith W: Experience of appearance-related teasing and bullying in skin diseases and their psychological sequelae: Results of a qualitative study. Scand J Caring Sci 22: 430-436, 2008.

47. Steinhausen HC: The heterogeneity of causes and courses of attention-deficit/hyperactivity disorder. Acta Psychiatr Scand 120: 392-399, 2009

48. Hammerness P, Monuteaux MC, Faraone SV, Gallo L, Murphy H and Biederman J: Reexamining the familial association between asthma and ADHD in girls. J Atten Disord 8: 136-143, 2005.

49. Tsai CJ, Chou PH, Cheng C, Lin CH, Lan TH and Lin CC: Asthma in patients with attention-deficit/hyperactivity disorder: A nationwide population-based study. Ann Clin Psychiatry 26: 254-260, 2014

50. Chen MH, Su TP, Chen YS, Hsu JW, Huang KL, Chang WH, Chen TJ and Bai YM: Asthma and attention-deficit/hyperactivity disorder: A nationwide population-based prospective cohort study. J Child Psychol Psychiatry 54: 1208-1214, 2013.

51. Buske-Kirschbaum A, Schmitt J, Plessowa F, Romanos M, Weidinger S and Roessner V: Psychoendocrine and psychoneuroimmunological mechanisms in the comorbidity of atopic eczema and attention deficit/hyperactivity disorder. Psychoneuroendocrinology 38: 12-23, 2013.

52. Banks WA and Erickson MA: The blood-brain barrier and immune function and dysfunction. Neurobiol Dis 37: 26-32, 2010.

53. Russell VA: Overview of animal models of attention deficit hyperactivity disorder (ADHD). Curr Protoc Neurosci Chapter 9: Unit 9.35,2011.

54. Tsai SJ: Signal transducer and activator of transcription 6 (STAT6) and attention-deficit hyperactivity disorder: A speculative hypothesis. Med Hypotheses 67: 1342-1344, 2006.

55. Shaw P, Lerch J, Greenstein D, Sharp W, Clasen L, Evans A, Giedd J, Castellanos FX and Rapoport J: Longitudinal mapping of cortical thickness and clinical outcome in children and adolescents with attention-deficit/hyperactivity disorder. Arch Gen Psychiatry 63: 540-549, 2006

56. Rosenkranz MA, Busse WW, Johnstone T, Swenson CA, Crisafi GM, Jackson MM, Bosch JA, Sheridan JF and Davidson RJ: Neural circuitry underlying the interaction between emotion and asthma symptom exacerbation. Proc Natl Acad Sci USA 102: 13319-13324, 2005.

57. Bieber T: Atopic dermatitis. N Engl J Med 358: 1483-1494, 2008

58. Schlotz W and Phillips DI: Fetal origins of mental health: Evidence and mechanisms. Brain Behav Immun 23: 905-916, 2009.

59. Ling EM, Smith T, Nguyen XD, Pridgeon C, Dallman M, Arbery J, Carr VA and Robinson DS: Relation of $\mathrm{CD} 4^{+} \mathrm{CD} 25^{+}$ regulatory $\mathrm{T}$ cell suppression of allergen-driven $\mathrm{T}$-cell activation to atopic status and expression of allergic disease. Lancet 363: 608-615, 2004

60. Akdis M, Verhagen J, Taylor A, Karamloo F, Karagiannidis C, Crameri R, Thunberg S, Deniz G, Valenta R, Fiebig H, et al: Immune responses in healthy and allergic individuals are characterized by a fine balance between allergen-specific T regulatory 1 and T helper 2 cells. J Exp Med 199: 1567-1575, 2004.

61. Carmi-Levy I, Homey B and Soumelis V: A modular view of cytokine networks in atopic dermatitis. Clin Rev Allergy Immunol 41: 245-253, 2011

62. Lou W, Wang C, Wang Y, Han D and Zhang L: Responses of CD4(+) CD25(+) Foxp3(+) and IL-10-secreting type I T regulatory cells to cluster-specific immunotherapy for allergic rhinitis in children. Pediatr Allergy Immunol 23: 140-149, 2012.

63. Chida Y, Hamer M and Steptoe A: A bidirectional relationship between psychosocial factors and atopic disorders: A systematic review and meta-analysis. Psychosom Med 70: 102-116, 2008.

64. Chang HY, Seo JH, Kim HY, Kwon JW, Kim BJ, Kim HB, Lee SY, Jang GC, Song DJ, Kim WK, et al: Allergic diseases in preschoolers are associated with psychological and behavioural problems. Allergy Asthma Immunol Res 5: 315-321, 2013. 
65. Bekdas M, Tufan AE, Hakyemez IN, Tas T, Altunhan H, Demircioglu F and Kismet E; Abant Izzet Baysal University Faculty of Medicine: Subclinical immune reactions to viral infections may correlate with child and adolescent diagnosis of attention-deficit/hyperactivity disorder: A preliminary study from Turkey. Afr Health Sci 14: 439-445, 2014.

66. Passarelli F, Donfrancesco R, Nativio P, Pascale E, Di Trani M, Patti AM, Vulcano A, Gozzo P and Villa MP: Anti-Purkinje cell antibody as a biological marker in attention deficit/hyperactivity disorder: A pilot study. J Neuroimmunol 258: 67-70, 2013.

67. Instanes JT, Halmøy A, Engeland A, Haavik J, Furu K and Klungs $\varnothing \mathrm{yr} \mathrm{K}$ : Attention-deficit/hyperactivity disorder in offspring of mothers with inflammatory and immune system diseases. Biol Psychiatry 81: 452-459, 2017.

68. Riazi K, Galic MA, Kuzmiski JB, Ho W, Sharkey KA and Pittman QJ: Microglial activation and TNF alpha production mediate altered CNS excitability following peripheral inflammation. Proc Natl Acad Sci USA 105: 17151-17156, 2008.

69. Mayer EA: Gut feelings: The emerging biology of gut-brain communication. Nat Rev Neurosci 12: 453-466, 2011.

70. Maranduba CM, De Castro SB, de Souza GT, Rossato C, da Guia FC, Valente MA, Rettore JV, Maranduba CP, de Souza CM, do Carmo AM, et al: Intestinal microbiota as modulators of the immune system and neuroimmune system: Impact on the host health and homeostasis. J Immunol Res 2015 : 931574, 2015.

71. Stofilová J, Szabadosová V, Hrčková G, Salaj R, Bertková I, Hijová E, Strojný L and Bomba A: Co-administration of a probiotic strain Lactobacillus plantarum LS/07 CCM7766 with prebiotic inulin alleviates the intestinal inflammation in rats exposed to N,N-dimethylhydrazine. Int Immunopharmacol 24 361-368, 2015
72. Maynard CL, Elson CO, Hatton RD and Weaver CT: Reciprocal interactions of the intestinal microbiota and immune system. Nature 489: 231-241, 2012.

73. Petra AI, Panagiotidou S, Hatziagelaki E, Stewart JM, Conti P and Theoharides TC: Gut-microbiota-brain axis and its effect on neuropsychiatric disorders with suspected immune dysregulation. Clin Ther 37: 984-995, 2015.

74. Zhou R, Han X, Wang J and Sun J: Baicalin may have a therapeutic effect in attention deficit hyperactivity disorder. Med Hypotheses 85: 761-764, 2015.

75. Shan Z, Zubcevic J, Shi P, Jun JY, Dong Y, Murça TM, Lamont GJ, Cuadra A, Yuan W, Qi Y, et al: Chronic knockdown of the nucleus of the solitary tract AT1 receptors increases blood inflammatory-endothelial progenitor cell ratio and exacerbates hypertension in the spontaneously hypertensive rat. Hypertension 61: 1328-1333, 2013.

76. Sagvolden T, Johansen EB, Wøien G, Walaas SI, Storm-Mathisen J, Bergersen LH, Hvalby O, Jensen V, Aase H, Russell VA, et al: The spontaneously hypertensive rat model of ADHD-the importance of selecting the appropriate reference strain. Neuropharmacology 57: 619-626, 2009.

77. Eigenmann PA: Diagnosis of allergy syndromes: Do symptoms always mean allergy? Allergy 60 (Suppl 79): S6-S9, 2005. 